\title{
Traceability of Machining CutTing Tools AND Fixtures In The Production System USING THE RFID TECHNOLOGY
}

\author{
LAZAREVIC, M.; COSIC, I.; VUKELIC, DJ.; \\ SREMCEV, N.; \& BAJCETA, D.
}

Abstract: The purpose of this paper is to present possible aplication of RFID technology in traceability of machining cutting tools and fixtures. Aplication of RFID technology should provide easier and faster identification of machining cutting tools and fixtures in the production system. The paper presents the overall structure of aplied technology, description of particular system and subsystems and the structure and functioning of RFID technology for traceability of machining cutting tools and fixtures. In conclusion, at the end of paper, are analyzed the advantages and disadvantages of the system and suggested the directions of future research.

Key words: Traceability, Identification, Machining cutting tools and fixtures, Production system, RFID technology
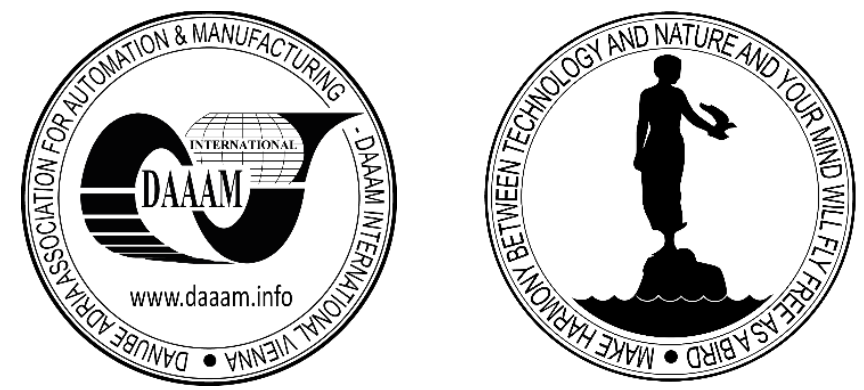

Authors' data: Univ.Prof. Dipl.-Ing. Dr Lazarevic, M[ilovan]; Univ.Prof. Dipl.-Ing. Dr Cosic, I[lija]; Univ.Prof. Dipl.-Ing. Dr Vukelic, Dj[ordje]; Univ.Teach.Assist. Dipl.-Ing. M.Sc. Sremcev, N[emanja]; Dipl.-Ing. M.Sc. Bajceta, D[ragan], University of Novi Sad, Faculty of Technical Sciences, Trg Dositeja Obradovica 6, 21000 Novi Sad, Serbia, laza@uns.ac.rs, ilijac@uns.ac.rs, vukelic@uns.ac.rs, nextesla@uns.ac.rs, dbajcetars@mts.rs.

This Publication has to be referred as: Lazarevic, M[ilovan]; Cosic, I[lija]; Vukelic, D[jordje]; Sremcev, N[emanja] \& Bajceta, D[ragan] (2015). Traceability of Machining Cutting Tools and Fixtures in the Production System Using the RFID Technology, Chapter 35 in DAAAM International Scientific Book 2015, pp.415-422, B. Katalinic (Ed.), Published by DAAAM International, ISBN 978-3-902734-05-1, ISSN 17269687, Vienna, Austria

DOI: $10.2507 /$ daaam.scibook.2015.35 


\section{Introduction}

The implementation of RFID technology in the supply chain, automated systems for identification and tracking of objects in industrial and non-industrial systems, are enabled research is several fields, like: manufacturing production, supply chain, access control, agricultural business, vending machines, payment, etc. (Stankovski \& Ostojic, 2013.). Fast launching of a novel product which beats the competition to the market, represents a key factor in providing larger market share at the world market, and higher profit for company.

All this requires development of flexible, agile manufacturing which is capable of rapid adjustment to novel manufacturing programs (Vukelic et al., 2011.). Having in mind stringent market demands and intensive development of science, equipment, and novel technologies, the level and trend of further development of machining processes in the metal cutting industry depend on numerous factors.

The factors which most influence quality of machining process are: type of blank, machining technology, operations, sub-operations, machine tools, cutting tools, fixtures, measuring devices, etc. (Vukelic et al., 2011.). In order to bring the machining process to a higher level, all these elements must be optimized (Todorovic et al., 2014.). For smaller companies, especially those which are struggling to find an appropriate position on the market, optimizing their production processes is a necessity (Debevc \& Herakovic, 2010).

Machining cutting tools and fixtures are the devices that are used in various processes which occur in industrial production systems (Fig. 1.). Without the use of machining cutting tools and fixtures of production process making the required dimensions and the required quality and necessary tolerances is practically impossible perform.

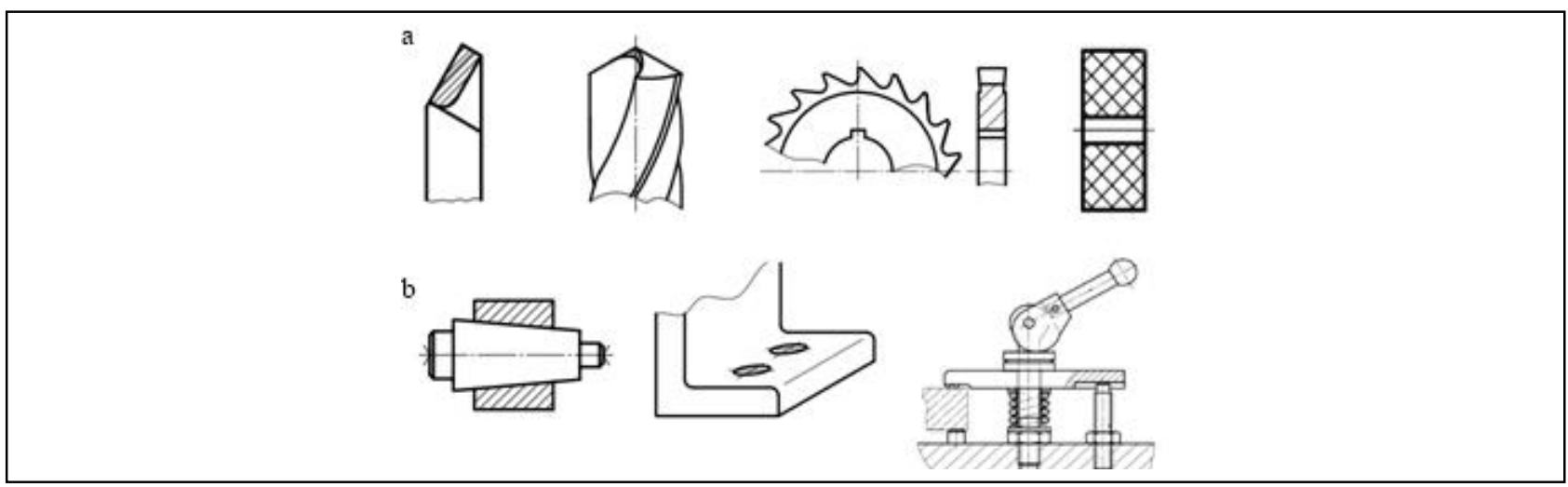

Fig. 1. (a) Machining cutting tools; (b) fixtures

One of the basic requirements of every production system is production optimization, which is the minimization of production time and costs, on the one hand, and maximization of profit, on the other (Ostojic et al., 2011.). The automation, in this case, mainly reflected in the process of automatic identification which can be realize through traceability machining cutting tools and fixtures using the RFID technology in the production process. Within this labor accent is placed on the promotion industrial production processes which is reflected in the shortening time of their duration and 
easier identification of components machining cutting tools and fixtures for machining treatment cutting.

In the previous period the attention of researchers the mostly focused on the use RFID technology for proces asembly/disassembly of the fixture and product (Vukelic et al., 2011., Ostojic et al., 2011., Lazarevic et al., 2006.). Also, the attention of research was use RFID technology for product tracking during life cycle (Ostojic \& Stankovski, 2011.). Other researchers have based their research on the analysis of the possible applications of RFID technology in a wide range (Rakic-Skokovic et al., 2008., Stankovski \& Ostojic, 2013). As was mentioned above, great care was dedicated to the process of assembly and disassembly of the fixture and product at the work place. The research process of the traceability and identification machining cutting tools and fixtures in the industrial production process from magazine, via work places i.e. handling, to repair place, is completely ignored.

Different research studies indicate the enormous loss of production time in machining, handling and assembly operations, caused mostly by the unavailability of resources (Debevc et al., 2014.). According to research carried out on time and costs in the production process significantly affects the ability or inability of the automatic identification and traceability of machining cutting tools and fixture. This conclusion indicates that special attention must paid to the traceability and identification of cutting tools and fixtures during moving through the production process so as to reduce the processing time and reduce overall costs production.

\section{Principles of RFID technology}

The actual and potential uses of RFID are wide-ranging and diverse. While many organizations are adopting RFID by force of mandate, even more of them are seeking ways to use the technology to improve their business processes (Rakic-Skokovic et al., 2008.). RFID tags, antennas and readers in practical use since the end of 1980. RFID technology has been developed in the Massachusetts Institute of Technology (MIT).

Radio frequency identification (RFID) is designed as a simple replacement of bar codes with which the object identification is done wirelessly, using radio waves. Using such a system removes some limitations that exist when using bar codes such as the need for direct visibility of the code by the reader, a small distance at which it can be read, the problems by wear or damage labels with bar code labels, slow at reading larger amounts of object, etc.

The main segments of the RFID system are:

- RFID tag.

- RFID reader/printer.

- Anntena.

- Computer (PC).

RFID tag is a carrier of information about the object, such as a bar code. It consists of a memory chip and a transmitter which communicates with the RFID reader (Fig. 2.). 


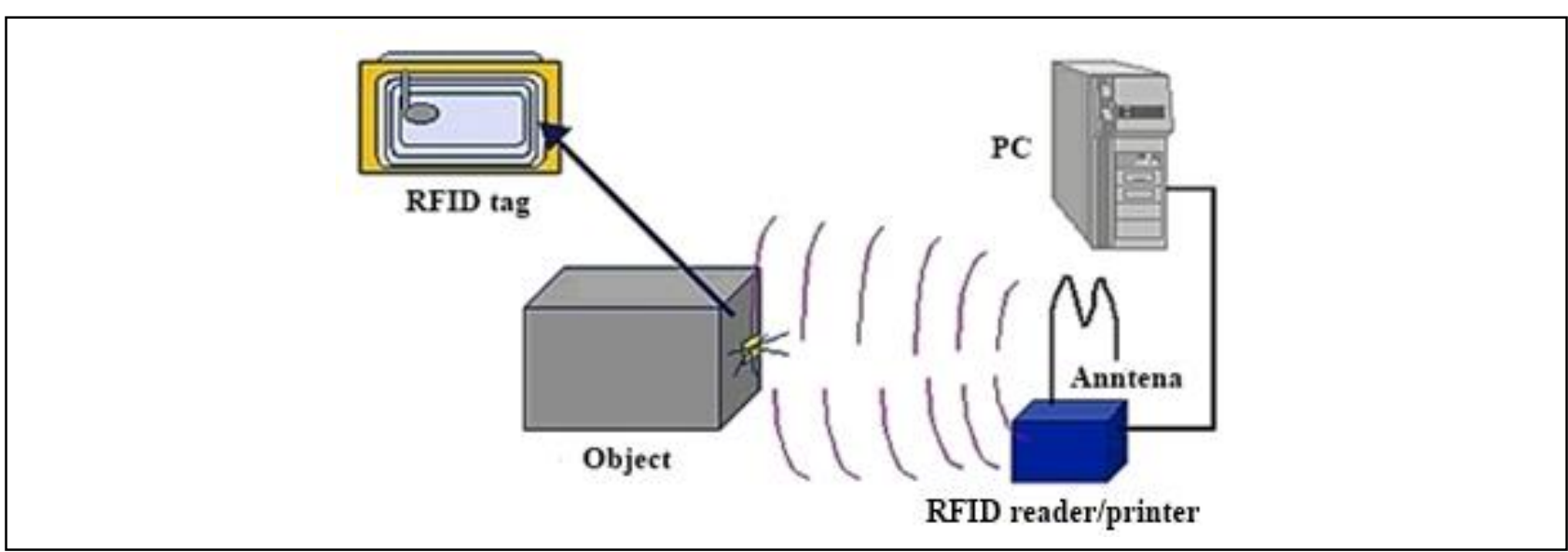

Fig. 2. RFID system

RFID reader/printer sends a signal to an antenna for a period of $50 \mathrm{~ms}$. Generated magnetic field accepts the antenna in a tag that is set to the same frequency as the reader. The received AC energy is stored in the mocro capacitor in the tag. When it finishes sending signals tag immediately transmits data stored in the microprocessor and memory tag. RFID device (reader or terminal to collect information) uses radio transmissions to send energy to transponder (RFID tag) which then emits feedback informations. The unique identification code and/or number of data previously stored in the transponder itself. Thus, the collected data, can be processed further. Data collected from the tag are sent directly to a computer via a standard interface (RS232/RS422), or saved to a portable reader and later transferred to a computer for data processing.

The most important characteristics of RFID systems include:

- Secure and unique identification.

- Durability and resistance to various identifiers specific environmental impacts.

- Easy to maintain because no moving parts.

- No needs direct visibility of identifiers.

- Achieved 99,5 to $100 \%$ reading accuracy in the first scan.

\section{Structural analysis of main system and subsystems required for traceability of machining cutting tools and fixtures}

Though there are the specialized factory for making machining cutting tools and fixtures, it is necessary that a company within their production system having and a toolroom, primarily due to the specifics of the production program, as well as the maintenance of the machining cutting tools and fixtures.

The term of the main system for traceability machining cutting tools and fixtures means the particulate system consisting of three subsystems which are formed on the basis of the three possible states of machining cutting tools and fixtures in the production system (Fig. 3.). These case include:

- Machining cutting tools and fixtures in magazine.

- Machining cutting tools and fixtures in handling.

- Machining cutting tools and fixtures on repair. 


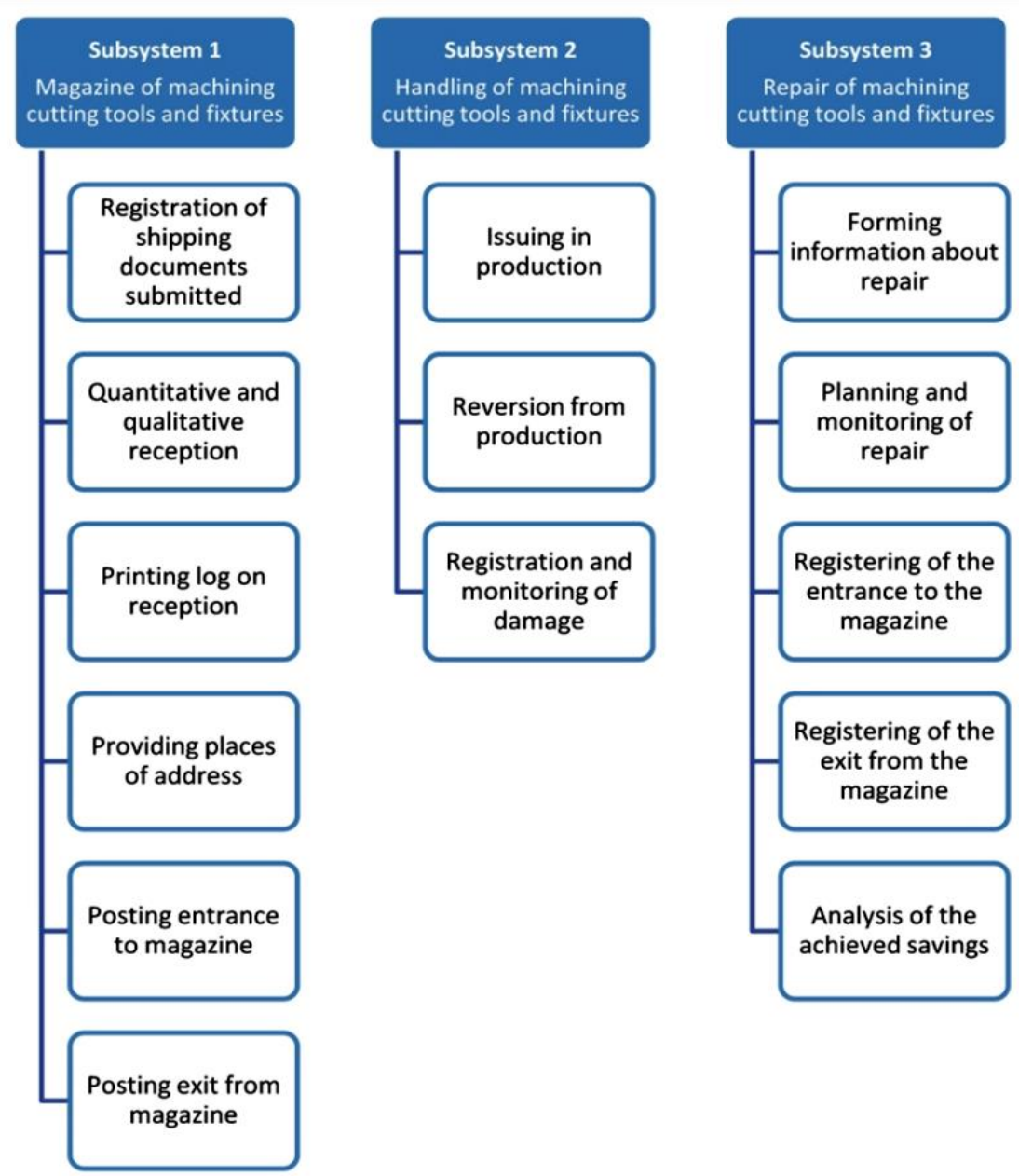

Fig. 3. Particular system for traceability of machining cutting tools and fixtures

he system for traceability machining cutting tools and fixtures is very important because for a smooth, planned, and high-quality production requires that the cutting tools and equipment to be promptly available and maximum quality. Also, this system is essential because it requires checking the influence of variations in quality when working with machining cutting tools and fixtures, which relate to the quality of product and the quality of functioning of the machining cutting tools and fixtures itself.

The magazine is done registration machining cutting tools and fixtures, its qualitative and quantitative analysis, printing log on reception, providing of address spaces for labeling, as well as posting the entrance to the magazine and exits from the magazine.

Handling the machining cutting tools and fixtures includes its issuing in the production, reversion from production, as well as registration and tracking damage.

Under repair machining cutting tools nad fixtures is meant to provide information about repairs, planning and monitoring repairs, registration input maching cutting tools and fixtures intended for the repair in magazine, registering output of machining cuting tools and fixtures intended for the repair from magazine and analysis of the achieved savings.

The above system can be automated using RFID systems to the entire process of tracking machining cutting tools and fixtures could take place more quickly and easily and to reduce the possibility of errors at the lowest possible level. 


\section{The structure and functioning of RFID technology for traceability of machining cutting tools and fixtures}

In order to RFID technology for tracking machining cutting tools and fixtures was fully functional, it must be connected with a computer and software system. This can be done by developing the complete structure of RFID technology for tracking machining cutting tools and fixtures, which integrates the computer and software system.

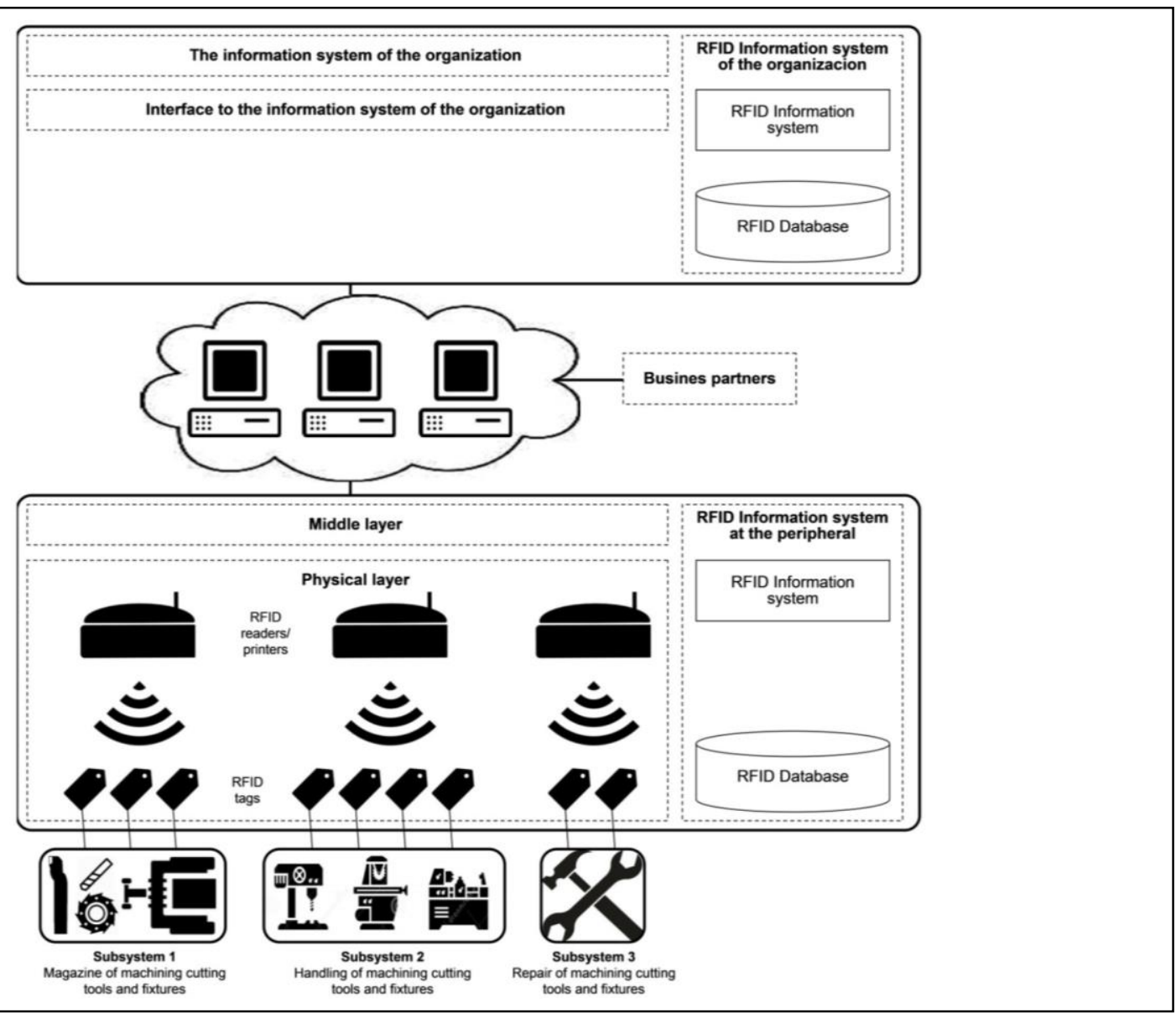

Fig. 4. The structure of the RFID technology for tracking machining cutting tools and fixtures

RFID technology has been deployed to various manufacturing objects through different schemes such as individual items, tray-based or container-based approach. Once the objects are tagged, they become smart objects (SOs) that can be traced and tracked. The data carried by them can be collected and are updated when their locations change from time to time. Meanwhile, data are transferred to enterprise information systems (EISs) through communication networks such as Bluetooth, Wireless $433 \mathrm{MHz}$ and TCP/IP (R.Y. Zhong, et al., 2013.).

For realization of the RFID technology for tracking the machining cutting tools and fixtures necessary to use all the elements of an RFID system.

The structure of the RFID technology for tracking machining cutting tools and fixtures consists of the following components (Fig. 4.):

- Components for the control of data collection (physical layer).

- The middle layer.

- Interface to the information system of the organization. 
- Information system organization.

Components for the control of data collection (physical layer) includes RFID tags, readers/printers, antennas and opcional sensors.

The middle layer includes the separation of the components of the physical layer of the component interface to the information system of the organization.

Interface to the information system of the organization has the task of integrating component of the middle layer with the existing information system of organization, ie. this component has the task of integrating business processes.

The information system of the organization includes a full range of applications and technology information system organization. It includes a data storage and starting of all business processes in the organization.

On admission to the magazine all the important information about machining cutting tools and fixtures are placed on the tag/tags from the person who is responsible for it. Depending on the needs and opportunities that dictates the production environment tag is then placed on the machining cutting tools and fixtures or to the appropriate box with machining cutting tools and fixtures. That marked machining cutting tools and fixtures to put in its place, and its data can be read and modified by the RFID reader/printer.

By placing RFID readers at each position workplace (machine) within the production system, it is based on a unique code associated with the tag reading time and location information, to obtain information on the position of the machining cutting tools and fixtures, its state and the time of incoming at the workplace (machine) and exit from the workplace (machine).

When the machining cutting tools and fixtures on the repair, the type of repair, as well as data about savings achieved by repairing machining cutting tools and fixtures, it is also possible to set the RFID reader in the tool room order to be able to tracking the availability of machining cutting tools and fixtures in real time, via a tag that is on the machining cutting tools and fixtures. Since RFID system allows data entry on the tag, these data can be related to the time of incoming to the repair and exit from the repair.

\section{Conclusion}

To solve the problem of tracking machining cutting tools and fixtures, which will be able bring benefits in terms of optimization of the production process and all the planned savings that optimization brings, used the possibility to integrate RFID technology into the production system.

Small and cheap electronic elements, e.g. tags, are enabled development of the tracking devices. These characteristics with communication are important to connection with wide range of devices, such as: computers, controllers, phones, etc. With these opportunities RFID technology can be used in nearly every business in the world. Among these business is the task that is present in this paper, i.e. tracking machining cutting tools and fixtures in the production system.

Using data carriers (tags) to machining cutting tools and fixtures, each of these objects carries complete data unite his identity, status, his past and future. There exists the possibility to change the data on machinig cutting tools and fixtures, which are located on the tag, at every stage of the manufacturing process, 
means that it is possible to create a flow of information between the individual points of the process, which reduces the load management system. Production operations and processing are becoming faster, and the fact that information about machining cutting tools and fixtures can be sent along with them and that it is possible now to access, creates the conditions for speeding up the production process.

Given the deficiencies, which are reflected in the fact that RF waves bounce off metal which can cause problems when reading tags, and given the current high price tags and complexity of deploying of this system, future research should be directed towards finding a ways to eliminate identified deficiencies.

\section{References}

Vukelic, Dj.; Ostojic G.; Stankovski, S.; Lazarevic, M.; Tadic, B.; Hodolic, J. \& Simeunovic, N. (2011). Machining fixture assembly/disassembly in RFID environment, Assem. Autom. 31 62-68

Ostojic, G.; Stankovski, S.; Vukelic, Dj.; Lazarevic, M.; Hodolic, J.; Tadic, B. \& Odri, S. (2011). Implementation of automatic identification technology in a process of fixture assembly/disassembly, Strojniski Vestn.-J. Mech. Eng. 57 819825

Ostojic, G. \& Stankovski, S. (2011). Systems and equipment for product tracking during life cycle, Faculty of Technical Sciences, For the purpose of TEMPUS project: Master studies and continuing education network for product lifecycle management with sustainable production, MAS-PLM Tempus JP - Agreement No: 144959-TEMPUS-2008-IT-JPRC, Novi Sad, ISBN 978-86-7892-403-3

Zhong, R.Y.; Dai, Q.Y.; Qu, T.; Hu, G.J. \& Huang, G.Q. (2013). RFID-enabled real-time manufacturing execution system for mass-customization production, Robot. Comput.-Integr. Manuf. 29 283-292

Todorovic, P.; Vukelic, Dj.; Tadic, B.; Veljkovic, D.; Budak, I.; Macuzic, I. \& Lalic, B. (2014). Modelling of dynamic compliance of fixture/workpiece interface, Int. J. Simul. Model. 13 54-65

Lazarevic, M.; Cosic, I. \& Anisic, Z. (2006). RFID Tehnologies In Product Disassembly Process, in: B. Katalinic (Ed.), 17. DAAAM International Symposium, DAAAM International, Vienna, pp. 129-137

Debevc, M. \& Herakovic, N. (2010). Management of resources in small and medium-sized production enterprises, Iranian journal of science and technology, Transaction B, Technology, vol. 34, no. B5, pp. 509-520, ISSN 1028-6284.

Debevc, M.; Simic, M. \& Herakovic, N. (2014). Virtual factory as an advanced approach for production process optimization, International journal of simulation modelling, vol. 13, no. 1, pp. 66-78, ISSN 1726-4529

Rakic-Skokovic, M.; Ostojic, G.; Lazarevic, M. \& Stankovski, S. (2008). Improving Business Processes With RFID Technology, DAAAM International Vienna, Vol. 19, No 1, pp. 161-168, ISSN 1726-9679, ISBN 978-3-901509-68-1. Stankovski, S. \& Ostojic, G. (2013). Challenges in Implementation of Automated Identification Technology, Chapter 02, DAAAM International Scientific Book, pp. 053-074, B. Katalinic \& Z. Tekic (Eds.), Published by DAAAM International, ISBN 978-3-901509-94-0, ISSN 1726-9687 